\title{
Magnetospheric convection from Cluster EDI measurements compared with the ground-based ionospheric convection model IZMEM
}

\author{
M. Förster ${ }^{1}$, Y. I. Feldstein ${ }^{2}$, S. E. Haaland ${ }^{3,4}$, L. A. Dremukhina ${ }^{2}$, L. I. Gromova ${ }^{2}$, and A. E. Levitin ${ }^{2}$ \\ ${ }^{1}$ Helmholtz-Zentrum Potsdam, GFZ German Research Centre for Geosciences, 14473 Potsdam, Germany \\ ${ }^{2}$ Institute of Terrestrial Magnetism, Ionosphere, and Radiowave Propagation, Troitsk, Russia \\ ${ }^{3}$ Max-Planck-Institut für Sonnensystemforschung, Lindau-Katlenburg, Germany \\ ${ }^{4}$ Department of Physics and Technology, University of Bergen, Norway
}

Received: 3 April 2009 - Revised: 13 July 2009 - Accepted: 6 August 2009 - Published: 7 August 2009

\begin{abstract}
Cluster/EDI electron drift observations above the Northern and Southern polar cap areas for more than seven and a half years (2001-2008) have been used to derive a statistical model of the high-latitude electric potential distribution for summer conditions. Based on potential pattern for different orientations of the interplanetary magnetic field (IMF) in the GSM y-z-plane, basic convection pattern (BCP) were derived, that represent the main characteristics of the electric potential distribution in dependence on the IMF. The BCPs comprise the IMF-independent potential distribution as well as patterns, which describe the dependence on positive and negative IMF $B_{z}$ and IMF $B_{y}$ variations. The full set of BCPs allows to describe the spatial and temporal variation of the high-latitude electric potential (ionospheric convection) for any solar wind IMF condition near the Earth's magnetopause within reasonable ranges. The comparison of the Cluster/EDI model with the IZMEM ionospheric convection model, which was derived from ground-based magnetometer observations, shows a good agreement of the basic patterns and its variation with the IMF. According to the statistical models, there is a two-cell antisunward convection within the polar cap for northward IMF $B_{z}+\leq 2 \mathrm{nT}$, while for increasing northward IMF $B_{z}+$ there appears a region of sunward convection within the high-latitude daytime sector, which assumes the form of two additional cells with sunward convection between them for IMF $B_{z}+\approx 4-5 \mathrm{nT}$. This results in a four-cell convection pattern of the high-latitude convection. In dependence of the $\pm \mathrm{IMF} B_{y}$ contribution during sufficiently strong northward IMF $B_{z}$ conditions, a transformation to three-cell convection patterns takes place.
\end{abstract}

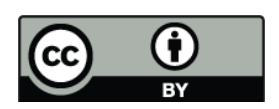

Correspondence to: M. Förster (mfo@gfz-potsdam.de)
Keywords. Magnetospheric physics (Plasma convection; Polar cap phenomena; Solar wind-magnetosphere interactions)

\section{Introduction}

Magnetospheric convection and its appearance as highlatitude ionospheric plasma convection depends strongly on the orientation of the Interplanetary Magnetic Field (IMF) carried by the solar wind and to a smaller extent on other solar wind parameters like solar wind speed and plasma density. It is generally accepted that the major driver of the large-scale internal convection of magnetospheric plasma and magnetic flux is magnetic field merging or reconnection between IMF and geomagnetic field lines at the magnetopause. Dungey (1961) explained in his pioneering paper the dependence of the basic twin cell convection pattern on the IMF orientation.

For southward IMF, reconnection on the dayside between IMF and closed geomagnetic field lines and reconnection on the nightside between field lines of both lobes result in the two main convection cells with antisunward plasma drift between them, when projected to the ionosphere. This closed loop reconnection sequence is now called "Dungey-cycle". A small fraction of the anti-sunward flow may occur on closed magnetic field lines due to quasi-viscous interaction between the solar wind and the magnetosphere at the magnetopause, as it was proposed by Axford and Hines (1961).

The IMF $B_{y}$ component modifies the twin-cell flow and leads to dawn-dusk asymmetries that are oppositely directed in the opposite hemispheres. This effect can be understood in terms of the tension exerted on newly reconnected field

Published by Copernicus Publications on behalf of the European Geosciences Union. 
lines in the presence of an IMF $B_{y}$ (e.g., Cowley and Lockwood, 1992), but also as the result of small latitudinal channels $\left(2^{\circ}-3^{\circ}\right.$ wide in magnetic latitude) of Pedersen current closure located poleward of the traditional R1-R2 current at the dusk- or dawn-side boundary of the polar cap and forming a part of a 3-D current system (Feldstein, 1976; Sandholt and Farrugia, 2009).

For northward IMF, Russell (1972) suggested that reconnection between the IMF and lobe field lines poleward of the cusp region can result in twin cell pattern at high latitudes in the ionosphere with sunward convection between them. This pattern is now known as lobe cell convection, which circulates exclusively in the open field line region of the polar cap. Tanaka (1999) showed in numerical simulations that reconnection between lobe and closed magnetospheric field lines is possible for near northward IMF conditions. Subsequently it was shown theoretically, that IMF-lobe reconnection in one hemisphere can be accomplished by lobe-closed reconnection in the other hemisphere, coupled by magnetic flux reciprocation (Watanabe et al., 2005). This results in a closed loop reconnection sequence, which Watanabe and Sofko (2009b) called the "interchange cycle". For a given IMF orientation close to northward, there usually exist according to this scenario two independent interchange cycles, which drive twin reverse cells at high latitudes $\left(>80^{\circ}\right)$ in both hemispheres covering both open and closed field line regions (Watanabe and Sofko, 2009a).

In case of northward IMF, the polarity of the IMF $B_{x}$ component was supposed to play a role as well. A negative IMF $B_{x}$ favours according to Crooker (1986) lobe reconnection in the Northern Hemisphere, whereas a positive IMF $B_{x}$ favours lobe reconnection in the Southern Hemisphere. However, no interhemispherical latitudinal differences in the cusp positions were found that could be attributed to the IMF $B_{x}$ component (Newell et al., 1989).

Empirical models of the high-latitude plasma convection, which describe the spatial and temporal variations of the convection pattern in magnetic coordinates (MLAT-MLT) and in dependence of the IMF and solar wind parameters, are mainly based on measurements onboard of low-altitude satellites like, e.g., OGO 6 (Heppner, 1977), DE 2 (Heppner and Maynard, 1987; Weimer, 1995, 2005), and DMSP (Rich and Hairston, 1994; Papitashvili and Rich, 2002) or alternatively on ground-based observations with radars (Ruohoniemi and Greenwald, 2005, SuperDARN) or magnetometer networks (Friis-Christensen et al., 1985; Feldstein and Levitin, 1986).

The IZMIRAN Electrodynamic Model (IZMEM) describes several high-latitude electodynamic parameters like the equivalent ionospheric current, the field-aligned current system, Joule heating rates, and the ionospheric plasma convection in dependence of the solar wind parameters. It is based on correlation analyses of the three-component magnetic field measurements of high-latitudes geomagnetic observatories with the observed IMF and solar wind varia- tions. The IZMEM model utilizes a linear regression between ground-based geomagnetic data of 14 magnetometer stations at northern high geomagnetic latitudes $>57^{\circ}$ and the IMF components $B_{x}, B_{y}$, and $B_{z}$ as well as the solar wind density and velocity (Feldstein et al., 1981; Levitin et al., 1982). The model was further developed and used subsequently in several detailed studies (Feldstein and Levitin, 1986; Papitashvili et al., 1994; Dremukhina et al., 1998).

In this paper, we present a model of high-latitude plasma convection based on measurements in the distant magnetosphere by use of the Electron Drift Instrument (EDI) onboard Cluster (Paschmann et al., 1997, 2001). EDI directly measures the full two-dimensional drift velocity perpendicular to the local geomagnetic field along the adjacent $4 R_{E} \times 19 R_{E}$ elliptical Cluster orbits with nearly $90^{\circ}$ inclination and orbital periods of about $57 \mathrm{~h}$. The spatially distributed EDI measurements are mapped to an ionospheric altitude of $400 \mathrm{~km}$ of the closest hemisphere, respectively, using the Tsyganenko-2001 magnetic field model (Tsyganenko, 2002a,b).

The method of data treatment, the derivation of statistical high-latitude convection patterns for certain IMF conditions, and the procedure of sorting for specified IMF directions (clock angles) is described in the companion papers of Haaland et al. (2007) and Förster et al. (2007). The EDI data set used for this study is similar to that used there, but covers now a longer time interval of seven and a two third years (February 2001 till September 2008). In contrast to those studies, we merge electric field measurements of the Southern and Northern Hemisphere in order to get a unified data set that represent summer season conditions of one hemisphere (North) to be compared with ground-based observations of a magnetometer network which forms the data base for the IZMEM model.

\section{The data}

We use EDI drift velocity or electric field $\mathbf{E}=-\mathbf{v} \times \mathbf{B}$ measurements obtained from three of the four Cluster satellites within the time interval from February 2001 until September 2008. EDI was not operational on Cluster-4, while data of Cluster-2 were available till April 2004 only. EDI measurements obtained at radial distances between $4 R_{E}$ and $15 R_{E}$ and at least $2 R_{E}$ earthward of the Shue et al. (1997) model magnetopause are retained for this study. They have been sampled to 1-min averages for mapping the drift vectors into the ionosphere assuming equipotential conditions along the geomagnetic field lines that are modeled with the Tsyganenko-2001 magnetic field model (Tsyganenko, 2002a,b). The mapped EDI drift vectors are binned and averaged in a high-latitude concentric grid in magnetic coordinates (MLAT-MLT) with bin sizes of $2^{\circ}$ in latitude and variable bin widths in longitude such that the bin area projected to the Earth's surface is nearly constant. 
The mapping of the drift vector into the ionosphere introduces some hard-to-quantify uncertainties, which might be caused by the model used. A detailed analysis of these uncertainties is beyond the scope of this paper. A comparison of the Cluster magnetic field measurements with the Tsyganenko-2001 model values was recently performed by Woodfield et al. (2007). They found that the model performs very well in a global sense. We expect that the mapping error is of the order or less than the bin size used.

The IZMEM model was in fact developed for both hemispheres and for summer, winter and equinox conditions separately (Feldstein and Levitin, 1986; Papitashvili et al., 1994), but for the present study we confine us to northern summer conditions only. Due to orbital constraints, the local time coverage of the Cluster data in each hemisphere is tightly correlated with season; during the northern summer (JuneAugust) the daytime-afternoon sector is covered, while during northern winter (December-February) it is the nighttime to early morning sector (cf., e.g., Haaland et al., 2007, Fig. 5). To obtain a global coverage for summer conditions in the Northern Hemisphere, we use data around the northern summer solstice (March to September) and project Southern Hemisphere observations of the half year around the southern summer solstice (September to March) into the Northern Hemisphere with the inverted sign of IMF $B_{y}$. We therefore neglect possible differences of the potential patterns in the opposite hemispheres for otherwise equal seasonal conditions and assume that the IMF $B_{y}+$ and $B_{y}-$ variations are mirror-symmetric for both hemispheres.

Measurements of the solar wind plasma parameters and the IMF are obtained from the Advanced Composition Explorer (ACE) spacecraft orbiting about the Earth-sun L1 libration point at a sunward distance of about $235 R_{E}$. We have used magnetic data from the ACE magnetic field instrument MAG (Smith et al., 1998) at $16 \mathrm{~s}$ resolution and from the solar wind instrument SWEPAM (McComas et al., 1998) at $64 \mathrm{~s}$ resolution. MAG and SWEPAM data are re-sampled to one minute time resolution, thereafter time shifted to represent the IMF conditions at the front side magnetopause (assumed to be located at $X_{\mathrm{GSE}}=10 R_{E}$ ).

We took much care to determine correct propagation delay times of the solar wind and IMF observations of ACE from its sunward outpost to their effectual domain at the magnetopause to compile reliable sets of concurrent IMF conditions. This procedure is described in detail in Haaland et al. (2007). This method applies the so-called phase front propagation technique proposed by Weimer et al. (2003) in the modification of the constrained minimum variance calculation MVAB-0 of Haaland et al. (2006).

\section{Potential distributions}

The usual way to represent high-latitude convection results is in terms of the electric potential distribution, $U$. The poten- tial is related to the convection electric field by the relation:

$\mathbf{E}=-\operatorname{grad} U$

The electric potential values, $U$, are found by minimizing the quantity $\chi^{2}$ given by

$\chi^{2}=\sum_{i=1}^{N}\left|\mathbf{E}_{i}+\operatorname{grad} U\right|^{2}$

where the electric field vectors, $\mathbf{E}_{i}$, are obtained as the cross products between the mapped convection vectors and the local ionospheric magnetic field at each valid grid point ( $N=784$ in this case). The potential is expanded as a function of magnetic co-latitude $\theta$ and magnetic local time MLT (here represented by the azimuthal angle $\phi$ ) in terms of spherical harmonic functions (Haines, 1985) :

$$
\begin{aligned}
U(\theta, \phi) & =\sum_{l=0}^{L} A_{l 0} P_{l}^{0}(\cos \theta) \\
& +\sum_{l=0}^{L} \sum_{m=0}^{l}\left(A_{l m} \cos m \phi+B_{l m} \sin m \phi\right) P_{l}^{m}(\cos \theta)
\end{aligned}
$$

where $P_{l m}$ are the associated Legendre polynomials and $A_{l m}, B_{l m}$ are the real-valued coefficients determined by the singular values of the $N \times K$ matrix, with $N$ being the number of grid points, and $K$ the number of coefficients. The spatial resolution is determined by the order $L$ and the degree (running index $m$ ) of the associated Legendre polynomials. In case of equal order and degree of the expansion, like in our study, the number of coefficients is $K=(L+1)^{2}$. In accordance with, e.g., Ruohoniemi and Greenwald (2005), we used $L=8$ for the EDI data representation throughout this paper. An absolute potential is obtained by assuming zero potential values at the outer, equatorward boundary $\theta_{\max }$, which is taken at $58^{\circ}$ magnetic latitude. For more details of the EDI Cluster data processing, the reader is referred to the methodological paper of Haaland et al. (2007). This spherical cap harmonic analysis is applied in a very similar way and up to the same order and degree of expension for the IZMEM model as described by Dremukhina et al. (1998).

Figure 1 shows high-latitude potential patterns in magnetic (AACGM) coordinates, sorted for eight different orientations (sectors) of the IMF, describing clock angle ranges in the GSM y-z-plane for the concurrent near-Earth interplanetary conditions that are derived from the delayed ACE observations as described above. Each sector comprises $45^{\circ}$ and their center positions are spaced by $45^{\circ}$. Sector 0 has a strict northward IMF direction, sector 2 points toward IMF $B_{y}+$, sector 4 southward, and sector 6 toward IMF $B_{y}-$, respectively. The odd number sectors are in between these principal directions. Table 1 lists the average values of the IMF $B_{y}$ and $B_{z}$ components for all the data points that were used for the construction of each individual sector's potential pattern. The average magnitude of the IMF in the GSM y-z-plane is of the order of $B_{T} \sim 4.5-5.0 \mathrm{nT}$. 

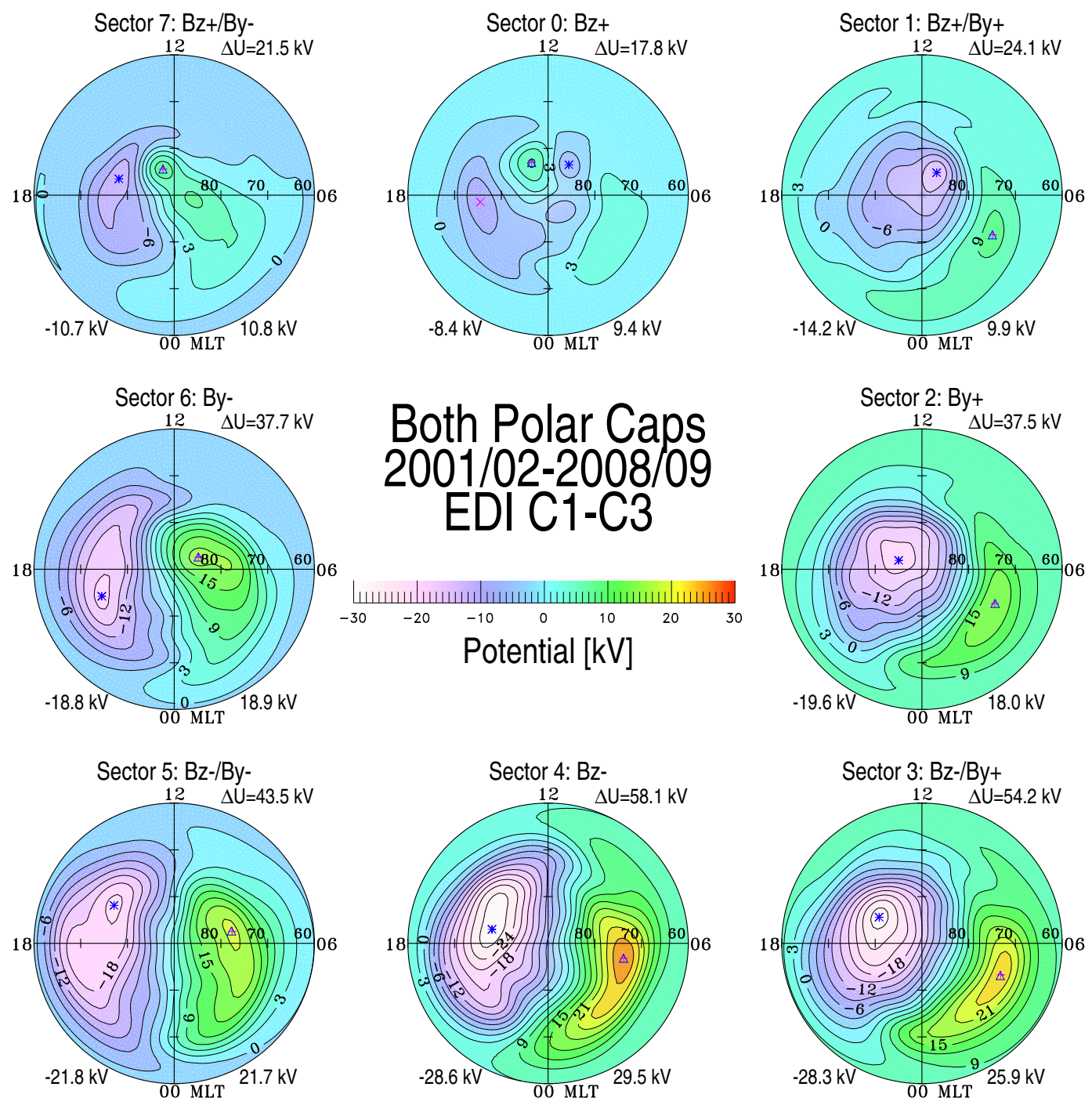

Fig. 1. Electric potentials obtained from Cluster EDI measurements for summer conditions at both North and South Hemispheres, projected into the Northern Hemisphere. Southern Hemisphere data points have been included with the inverted sign of IMF $B_{y}$. The potentials are shown as a function of magnetic latitude and magnetic local time for 8 clock-angle orientations (sectors) of the IMF. The background colour shows the potential value, according to the colour bar in the center, while the lines are drawn at fixed potential values with a $3 \mathrm{kV}$ spacing. The minimum and maximum potentials are listed at the bottom, and the total cross-polar potential drop at the upper right of each dial.

As outlined in Sect. 2 already, these high-latitude potential pattern represent summer conditions of both hemispheres merged together, but they are practically nearly identical to the pattern shown in Haaland et al. (2007, Fig. 7), which are based on data of the full year. They are also very similar to those potential plots obtained from ground-based radar observations as, e.g., the SuperDARN pattern of Ruohoniemi and Greenwald (2005, Fig. 6) for average IMF magnitudes. Similar potential patterns result as well from the parametrized empirical IZMEM model (e.g., Dremukhina et al., 1998), which is based on measurements of a magnetometer network on Earth's surface and a conductance model of the ionosphere. A more detailed comparison will follow in the subsequent section.
The following large-scale characteristics of the potential pattern in Fig. 1 can be noticed:

i) independent of the IMF orientation, there always exists the familiar two-cell convection pattern with antisunward convection between them over the polar cap;

ii) for IMF $B_{z}<0$, the two-cell antisunward convection pattern in the polar cap intensifies, which can be interpreted as an additional two-cell pattern with antisunward convection, overlayed on the similar pre-existing two-cell background pattern;

iii) for IMF $B_{z}>0$, there appears an additional pair of convection cells at high latitudes $\left(>80^{\circ}\right)$ with sunward 
Table 1. Averages of the IMF $B_{y}$ and $B_{z}$ component values at the magnetopause for all those data points used for the construction of the potential pattern of the respective sector.

\begin{tabular}{clrr} 
Sector & IMF orientation & $<B_{y}>$ & $<B_{z}>$ \\
\hline 0 & $B_{z}+$ & 0.00068 & 3.641 \\
1 & $B_{z}+/ B_{y}+$ & 3.205 & 2.749 \\
2 & $B_{y}+$ & 4.531 & -0.047 \\
3 & $B_{z}-/ B_{y}+$ & 3.263 & -2.761 \\
4 & $B_{z}-$ & -0.121 & -4.678 \\
5 & $B_{z}-/ B_{y}-$ & -3.847 & -3.347 \\
6 & $B_{y}-$ & -5.015 & -0.105 \\
7 & $B_{z}+/ B_{y}-$ & -3.505 & 3.002 \\
\hline
\end{tabular}

convection between them, which can be interpreted as an additional two-cell structure within the dayside polar cap, overlayed on the larger two-cell background and resulting in an overall four-cell convection pattern;

iv) with an increasing IMF $B_{y}$ component, the relative areas occupied by the positive and negative cells change with respect to each other, i.e, the area with negative (positive) potential increases for increasing IMF $B_{y}+$ (IMF $B_{y}-$ ) values, which is equivalent to an overlayed circular convection cell with negative (positive) potential, over the pre-existing two-cell background pattern.

Analogous to the variation of the geomagnetic field and the plasma convection in the IZMEM model formulation, the large-scale high-latitude potential pattern can be represented by a relation like the following:

$$
\begin{aligned}
U\left(\theta, \phi, B_{y}, B_{z}\right)=U_{0}(\theta, \phi) & +\hat{U}_{ \pm y}(\theta, \phi) \cdot\left( \pm B_{y}\right) \\
& +\hat{U}_{ \pm z}(\theta, \phi) \cdot\left( \pm B_{z}\right)
\end{aligned}
$$

where $U_{0}$ (in $\mathrm{kV}$ ) represents a constant term which is independent of the IMF, while the terms $\hat{U}_{ \pm y}$ and $\hat{U}_{ \pm z}($ in $\mathrm{kV} / \mathrm{nT}$ ) describe the linear dependencies on the IMF $B_{y}$ and $B_{z}$ components, respectively, normalized to $1 \mathrm{nT}$ variations, which can be different for different signs. Such a decomposition of the potential pattern dependencies has been used previously already by, e.g., Feldstein and Levitin (1986), Papitashvili and Rich (2002) and Kabin et al. (2003). It will be applied here for a generalized description of the Cluster potential pattern in dependence on the IMF $B_{y}$ and $B_{z}$ components as shown in Fig. 1 with the various sectors.

\section{Basic convection patterns}

The statistical pattern of Fig. 1 are obtained on average from moderate values of the IMF $B_{y}$ and $B_{z}$ components (see Table 1), which justifies to use a linear regression for the dependence of the convection intensity on the IMF components.
Figure 2 shows the four basic convection patterns (BCPs): $U_{0}(\theta, \phi)$ (upper left panel), $\hat{U}_{ \pm y}\left(\theta, \phi, B_{y}= \pm 1 \mathrm{nT}\right)$ (lower right), $\hat{U}_{+z}\left(\theta, \phi, B_{z}=+1 \mathrm{nT}\right.$ ) (upper right), and $\hat{U}_{-z}\left(\theta, \phi, B_{z}=-1 \mathrm{nT}\right)$ (lower left). They are derived from summations of various sector's potential pattern that are shown in Fig. 1: the "background" potential pattern $U_{0}$ for vanishing IMF $B_{y}$ and $B_{z}$ components results from the average of sectors 2 and 6 , while the IMF $B_{y}$ dependence $\hat{U}_{ \pm y}$ results from their difference, normalized to $1 \mathrm{nT}$ by dividing through the difference of the sector's $\left\langle B_{y}\right\rangle$ average values (Table 1). The dependence on variations of the IMF $B_{z}$ component with $\hat{U}_{+z}$ and $\hat{U}_{-z}$ is derived from differences between sectors 0 and 4 , respectively, to the "background" $U_{0}$. They are essentially different for the different signs.

The BCPs represent characteristic convection patterns for specific IMF conditions and the linear character of this representation allows to calculate convection pattern for any IMF conditions within reasonable ranges of applicability. In each panel of the potential representations, the minimum and maximum values of the main foci are indicated at the bottom and the cross-polar potential drop, $\Delta U$, is given in the upper right. Except of the "background" potential in the upper left panel, all BCPs are normalized to $1 \mathrm{nT}$ changes of the respective IMF component.

The two cells of the "background" potential pattern $U_{0}$, which is independent of any IMF $B_{y}$ and $B_{z}$ variation (Fig. 2, upper left panel), are nearly equal in intensity (the dusk cell being slightly stronger) and symmetric about the noonmidnight meridian with foci at about $75^{\circ}$ magnetic latitude near the 06:00-18:00 MLT meridian. The overall potential is about $\Delta U \sim 31 \mathrm{kV}$.

Similar to the $U_{0}$ pattern, the $\hat{U}_{-z}$ potential distribution (Fig. 2, lower left panel) forms a two-cell pattern with antisunward convection between the foci, which are located at $\approx 71^{\circ}-75^{\circ}$ magnetic latitude, the position of which is slightly turned clockwise from the dawn-dusk meridian. The two cells have about the same intensity (same absolut potential), but the dusk cell occupies a slightly larger area. The $\hat{U}_{+z}$ potential pattern, in contrary, shows a smaller-scale twocell convection pair at higher latitudes with the opposite (sunward) convection between their foci. The normalized potential drop between the foci is about the same for the opposite IMF $B_{z}$ variations with $\Delta U \sim 7 \mathrm{kV}$ for a $1 \mathrm{nT}$ change.

The $\hat{U}_{ \pm y}$ BCP (lower right panel), finally, shows essentially one large convection cell near the center of the polar cap with a minmum potential value of $\Delta U=-4.7 \mathrm{kV}$. The convection in this case (i.e., for IMF $B_{y}+$ at the Northern Hemisphere) is clockwise (CW) and it is counter-clockwise (CCW) for the opposite polarity IMF $B_{y}-$. The normalized potential drop is small in comparison with the IMF $B_{z}$ dependences with a $\Delta U$ of about $2 / 3$ of those potential magnitudes per $1 \mathrm{nT}$ change.

The BCPs can principally be estimated also with other combinations of the sector's pattern or with different choices 

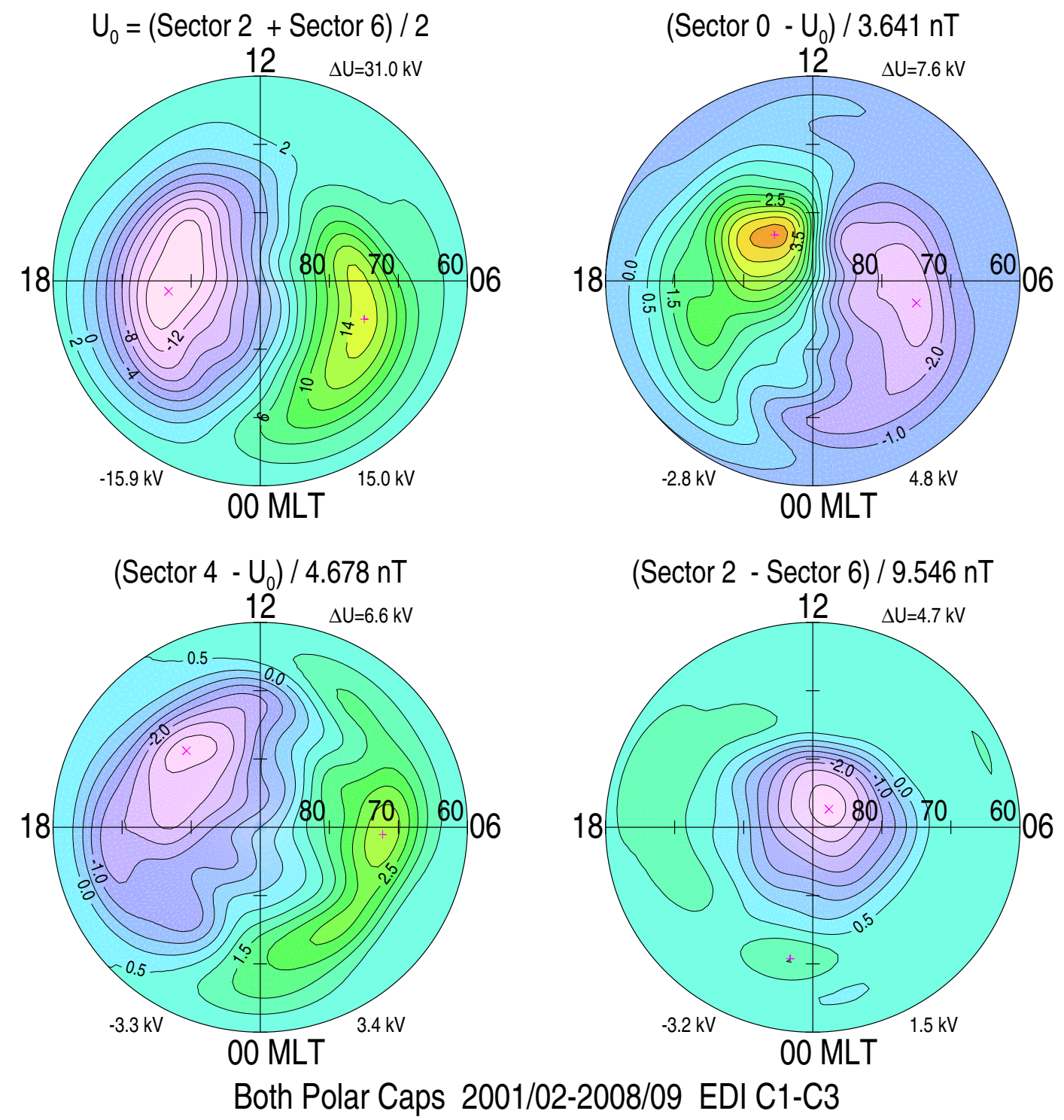

Fig. 2. Basic high-latitude convection patterns (BCPs) for summer conditions derived from EDI Cluster measurements sorted for different IMF orientations as shown in Fig. 1. The $U_{0}$ background potential for vanishing IMF $B_{y}$ and $B_{z}$ components (upper left panel) is derived as the sum of sectors 2 and 6 of Fig. 1, while the IMF $B_{y}$ dependence (lower right panel) is derived from their difference. The dependence on variations of the IMF $B_{z}$ component is shown separately for IMF $B_{z}+$ (upper right panel) and IMF $B_{z}-$ values (lower left panel) as derived from differences of sectors 0 and 4 , respectively, to the $U_{0}$ pattern.

of sector width. We have tested various combinations as, e.g., calculating the $\hat{U}_{-z}$ potential pattern by use of sectors 3 and 5 (and, correspondingly, $\hat{U}_{+z}$ with sectors 1 and 7 ) by calculating $\hat{U}_{-z}=\left(\right.$ sector $3+$ sector 5-2. $\left.U_{0}\right) / 6.24$ ) (figure not shown) and came to nearly identical potential pattern as shown in Fig. 2 and potential drops between the foci that where within $\Delta U \sim \pm 0.1 \mathrm{kV}$. This gives confidence in the validity of the BCPs derived, because they result from independent subsets of the EDI drift measurements.

Figure 3 shows the corresponding BCP representations for the IZMEM model (Northern Hemisphere, summer condi- tions), which are derived in a completely different manner. Based on ground-based observation of a magnetometer network at high latitudes, regression analyses are performed for the data sets of the individual magnetometer stations and the global pattern are then assembled using the spherical harmonic functions of Eq. (3). The comparison with the EDI Cluster results in Fig. 2 shows a good correspondence for all four BCPs.

The "background" potential pattern $U_{0}=31.9 \mathrm{kV}$ has about the same potential drop, but the connecting line between the foci appears to be turned clockwise. The $\hat{U}_{-z}$ 


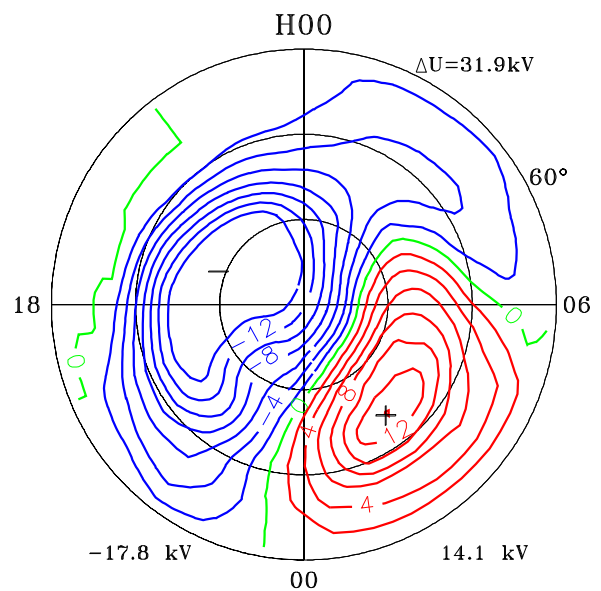

IZMEM model

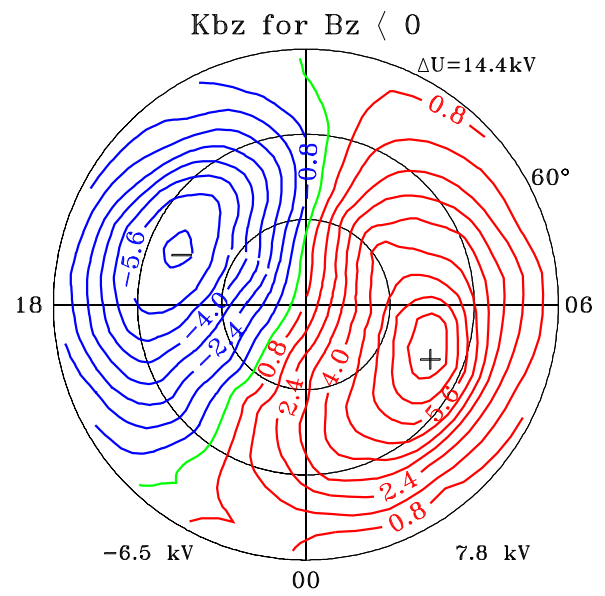

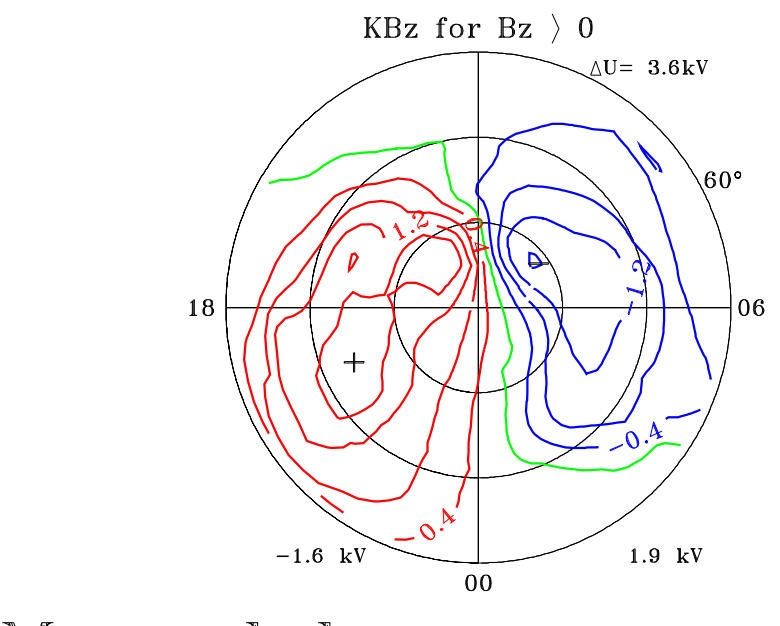

$\mathrm{KBz}$ for $\mathrm{Bz}>0$

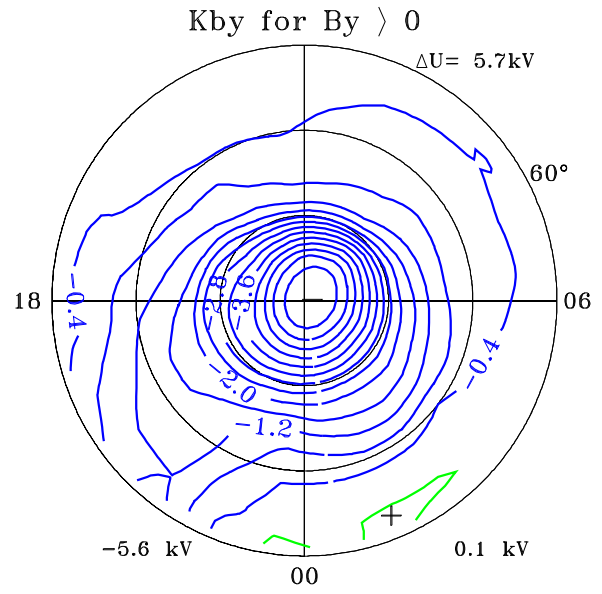

Fig. 3. Basic high-latitude convection patterns (BCPs) as shown in Fig. 2, but derived from the IZMEM model for summer solstice conditions in the Northern Hemisphere.

pattern has the same two-cell characteristics as the EDI Cluster data and with $\approx 14 \mathrm{kV}$ about a two times larger cross-polar potential per $1 \mathrm{nT}$ increase of IMF $B_{z}-$.

The $\hat{U}_{+z}$ pattern agrees similarly well in shape and position of the small high-latitude cell pair with sunward convection between them, but here we observe a potential drop of $\Delta U=-3.6 \mathrm{kV}$, which is about half of the corresponding values for the EDI Cluster data set. A close similarity is observed for the $\hat{U}_{ \pm y}$ pattern with a potential minimum of $5.7 \mathrm{kV}$, the center of which practically coincides with the magnetic north pole.

The differences in the $\hat{U}_{-z}$ and $\hat{U}_{+z}$ patterns might be due to the fact, that the IZMEM results shown here are for the Northern Hemisphere only and the seasonal selection is more focused on summer conditions, because only data from the months June to August have been used. It can be also caused by some other systematic differences between ground-based observations and pattern that are derived from in-situ mag- netospheric measurements under various assumptions. This needs further study.

\section{Discussion}

The superposition of the BCPs, scaling their intensity with the actual values of the IMF components, allows to model the high-latitude plasma convection for a wide range of IMF input values. One example is given in Fig. 4 for the EDI data under northward IMF conditions, as it was studied in the paper of Förster et al. (2008). There the authors had studied the variation of the convection pattern in dependence of small deviations $\left(\approx \pm 30^{\circ}\right)$ of the IMF clock angle from purely northward direction and further they showed the different convection patterns at zero clock angle obtained separately for $B_{z}<5 \mathrm{nT}$ and $B_{z}>5 \mathrm{nT}$ (Förster et al., 2008, Fig. 7). They demonstrated that the four-cell convection pattern is present 

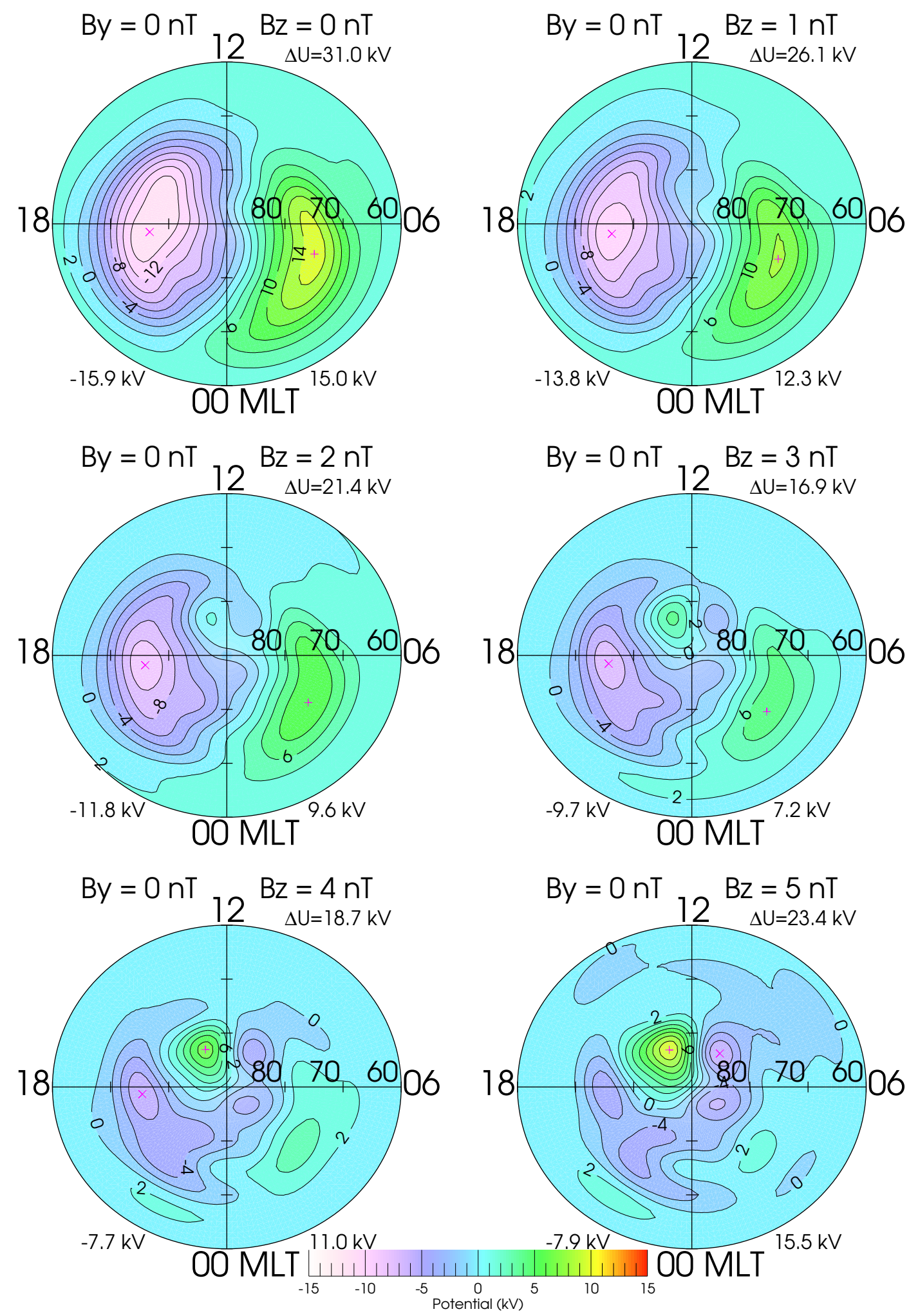

Fig. 4. These six potential patterns show statistical EDI Cluster results for purely northward IMF, deduced from the BCPs in Fig. 2. The values of the $B_{z}$ component vary in steps of $1 \mathrm{nT}$ from $B_{z}=0 \mathrm{nT}$ to $B_{z}=5 \mathrm{nT}$. The colour scale of the potential values (kV) is indicated at the bottom. The "+" and "x" signs indicate the positions of the absolute maximum and minimum potential values, respectively. Note that the maximum potential difference is between the main cells in the first four panels, jumps to the two cells on the dusk side, and finally to the two minor high latitude cells on the dayside with sunward drift between them in the last panel on the bottom right. 
for both subsets, but for the latter the small high-latitude pair of cells with sunward convection between their foci is much more intense.

Figure 4 presents six potential patterns for purely northward IMF with different values of the $B_{z}$ component, which varies in steps of $1 \mathrm{nT}$ from $B_{z}=0 \mathrm{nT}$ to $B_{z}=5 \mathrm{nT}$. A two-cell pattern with antisunward convection prevails for the interval $0 \mathrm{nT} \leq B_{z}<2 \mathrm{nT}$. Beginning with $B_{z}=2 \mathrm{nT}$, a second pair of convection cells with sunward drift between them appears on the dayside at high latitudes $\gtrsim 80^{\circ}$, which is fully developed for $B_{z}=3 \mathrm{nT}$. The larger convection cells at lower latitudes with antisunward drift between them still prevail in strength. For $B_{z}=5 \mathrm{nT}$, finally, the high-latitude sunward convection cell pair dominates over the antisunward cells at lower latitudes. The BCP modelling of the EDI Cluster data therefore confirms the different patterns for different $B_{z}$ magnitudes in Fig. 7 of Förster et al. (2008). The addition of an IMF $B_{y}$ component to the IMF $B_{z}+$ system will result in a three-cell system, depending on the strength of the $\hat{U}_{ \pm y}$ contribution, as it was shown there as well with respect to clock angle changes.

The good agreement of BCPs derived from completely different data sets and methods of data reduction as shown in Fig. 2 (EDI Cluster satellite data) and Fig. 3 (ground-based magnetometer data) confirms the validity of the basic assumption about the linearity of the IMF component dependence and hence also the possibility to superpose the different BCP contributions. The detailed comparison shows minor differences in the shape of the patterns, in the position of the potential foci, and in the relative potential difference between them. One has to keep in mind, that the comparisons are done with statistically averaged data sets, so that significant differences have to be larger than the typical variances.

The difference in the position of the central focus for the $\hat{U}_{ \pm y}$ pattern (lower right panel in Figs. 2 and 3), for instance, between the IZMEM and the EDI Cluster data set of about $3^{\circ}$ can be considered to be insignificant. It might be due to the differences in spatial resolution in magnetic latitude within the central polar cap, which is of about that order for IZMEM, while the Cluster data have their best coverage just in this region and a spatial resolution of about $2^{\circ}$, i.e., the order of the grid spacing.

The "background" potential pattern $U_{0}$ (upper left panel in Figs. 2 and 3) constitute the steady state properties of magnetospheric convection for prolonged geomagnetic quiescence, associated with vanishing values of the IMF components. This is referred to as the "ground state" of the magnetosphere. The magnetospheric cavity, formed due to a steady, unmagnetized solar wind flow past the Earth's magnetic field, represents this ground state, when practically no reconnection takes place between the IMF and the Earth's field. Under such conditions, exclusively diffusive processes like viscous interaction at the magnetopause contribute to the generation of the magnetospheric convection.
Only a few experimental and theoretical studies of the magnetospheric ground state were performed, which come to similar conclusions about the transpolar potential under such conditions. Watanabe et al. (1998), using magnetic field and particle data of various satellites, showed that this ground state corresponds to a few tens of kilovolts, while Sonnerup et al. (2001) found in their theoretical simulation study that standard conditions with a solar wind velocity of $400 \mathrm{~km} / \mathrm{s}$ and a Pedersen conductivity of $\approx 6$ mho in the polar ionosphere result in a polar cap potential of $29.9 \mathrm{kV}$. This is remarkably close to the values of the $U_{0}$ patterns in this study.

The model representation using BCPs of the main contribution relies on the linear character of IMF dependencies, which allows their superposition. This approach is applicable only for "normal", moderate IMF conditions within reasonable ranges of the IMF $B_{y}$ and $B_{z}$ components; any extreme IMF values and rapidly changing conditions are certainly not correctly reproduced by this method. Due to the statistical background, the deduced BCPs represent "only" average, characteristic convection patterns for the specified IMF values.

It might be worth to investigate temporal changes of the potential pattern due to rapid changes of the IMF conditions at the background of this quasi-static BCP model. Intercomparisons between different models of the high-latitude plasma convection, which are based on different observations of complementary data sets and different methods of their data reduction, should be continued. To do this, the BCPs are a valueable tool for the study of their agreement or possible disagreement in a statistical sense.

\section{Conclusions}

More than seven and a half years of EDI Cluster measurements of the magnetospheric convection drift and concurrent observations of the IMF orientation with the ACE solar observatory at the L1 point upstream in the solar wind have been used to deduce statistical pattern of the ionospheric convection in dependence of the IMF orientation. Given a linear dependence on the IMF $B_{y}$ and $B_{z}$ components, as it was shown in various previous empirical models of the magnetospheric convection, four basic convection patterns (BCPs) can be deduced, which describe this dependence for any IMF component value within reasonable ranges.

All four BCPs appear as two-cell convection pairs (considering the $\hat{U}_{ \pm y}$ pair as residing in the opposite hemispheres). They represent accordingly the "background" convection, $U_{0}$, for vanishing IMF $B_{y}$ and $B_{z}$, which appears to be a symmetric two-cell pattern with antisunward convection between their foci, and the convection patterns $\hat{U}_{ \pm y}$ and $\hat{U}_{ \pm z}$ for describing variations with the corresponding IMF components. Those are normalized for $1 \mathrm{nT}$ steps of change in the component's magnitude. A two-cell antisunward convection pattern similar to the background cells is deduced for 
IMF $B_{z}-$, while the $B_{z}+$ variation reveals a smaller pair of sunward convection at higher magnetic latitudes $>80^{\circ}$. For IMF $B_{y}$ variations, one circular convection mode is deduced with its focus near the magnetic pole in the center of the polar cap.

The comparison of $\mathrm{BCP}$ representations obtained with EDI Cluster and the corresponding patterns of the IZMEM model shows a good agreement of their characteristics and for most of their potential values. Two completely different data sets and methods - the spatially distributed satellite measurements on the one hand and the ground-based magnetometer data on the other - confirm therefore the principal result, that the IMF dependence of the high-latitude plasma convection can be described as a superposition of a constant background convection and linear variations with the IMF $B_{y}$ and $B_{z}$ components. This is valid for quasi-static conditions and moderate IMF variations; extreme parameter conditions have to be considered separately. Further detailed studies and comparisons with other models should be performed.

Acknowledgements. Work at the Helmholtz Centre Potsdam, German Research Centre for Geosciences (M. F.), was supported by Deutsche Forschungsgemeinschaft (DFG) and work at the IZMIRAN by RFBR grants 07-05-13524 and 08-05-00896. Research at the University of Bergen (S. E. H.) was supported by the Norwegian Research Council. We thank the ACE SWEPAM and MAG instrument teams and the ACE Science Center for providing the ACE data.

Topical Editor I. A. Daglis thanks two anonymous referees for their help in evaluating this paper.

\section{References}

Axford, W. I. and Hines, C. O.: A unifying theory of high-latitude geophysical phenomena and geomagnetic storms, Can. J. Phys., 39, 1433-1464, 1961.

Cowley, S. W. H. and Lockwood, M.: Excitation and decay of solar wind-driven flows in the magnetosphere-ionosphere system, Ann. Geophys., 10, 103-115, 1992.

Crooker, N. U.: An evolution of antiparallel merging, Geophys. Res. Lett., 13, 1063-1066, 1986.

Dremukhina, L. A., Levitin, A. E., and Papitashvili, A. E.: Analytical representation of IZMEM model for near-real time prediction of electromagnetic weather, J. Atmos. Solar-Terr. Phys., 60, 1517-1529, 1998.

Dungey, J. W.: Interplanetary magnetic field and the auroral zones, Phys. Rev. Lett., 6, 47-48, 1961.

Feldstein, Y. I.: Magnetic field variations in the polar region during magnetically quiet periods and interplanetary magnetic fields, Space Sci. Rev., 18, 777-861, 1976.

Feldstein, Y. I. and Levitin, A. E.: Solar wind control of electric fields and currents in the ionosphere, J. Geomag. Geoelectr., 38, 1143-1182, 1986.

Feldstein, Y. I., Afonina, R. G., Belov, B. A., Levitin, A. E., and Sumaruk, P. V.: Ground geomagnetic field variations and field- aligned currents in the magnetosphere during periods of $B_{z}>0$ IMF component, Phys. Solariterr., 15, 57-70, 1981.

Förster, M., Paschmann, G., Haaland, S. E., Quinn, J. M., Torbert, R. B., Vaith, H., and Kletzing, C. A.: High-latitude plasma convection from Cluster EDI: variances and solar wind correlations, Ann. Geophys., 25, 1691-1707, 2007, http://www.ann-geophys.net/25/1691/2007/.

Förster, M., Haaland, S. E., Paschmann, G., Quinn, J. M., Torbert, R. B., Vaith, H., and Kletzing, C. A.: High-latitude plasma convection during Northward IMF as derived from in-situ magnetospheric Cluster EDI measurements, Ann. Geophys., 26, 26852700, 2008, http://www.ann-geophys.net/26/2685/2008/.

Friis-Christensen, E., Kamide, Y., Richmond, A. D., and Matsushita, S.: Interplanetary magnetic field control of high-latitude electric fields and currents determined from Greenland magnetometer data, J. Geophys. Res., 90, 1325-1338, 1985.

Haaland, S. E., Paschmann, G., and Sonnerup, B. U. Ö.: Comment on "A new interpretation of Weimer et al.'s solar wind propagation delay technique" by Bargatze et al., J. Geophys. Res., 111, A06102, doi:10.1029/2005JA011376, 2006.

Haaland, S. E., Paschmann, G., Förster, M., Quinn, J. M., Torbert, R. B., McIlwain, C. E., Vaith, H., Puhl-Quinn, P. A., and Kletzing, C. A.: High-latitude plasma convection from Cluster EDI measurements: method and IMF-dependence, Ann. Geophys., 25, 239-253, 2007, http://www.ann-geophys.net/25/239/2007/.

Haines, G. V.: Spherical cap harmonic analysis, J. Geophys. Res., 90, 2583-2591, 1985.

Heppner, J. P.: Empirical models of high-latitude electric fields, J. Geophys. Res., 82, 1115-1125, 1977.

Heppner, J. P. and Maynard, N. C.: Empirical high-latitude electric field models, J. Geophys. Res., 92, 4467-4489, 1987.

Kabin, K., Rankin, R., Marchand, R., Gombosi, T. I., Clauer, C. R., Ridley, A. J., Papitashvili, V. O., and DeZeeuw, D.: Dynamic response of Earth's magnetosphere to By reversals, J. Geophys. Res., 108, 1132, doi:10.1029/2002JA009480, 2003.

Levitin, A. E., Afonina, R. G., Belov, B. A., and Feldstein, Y. I.: Geomagnetic variations and field-aligned currents at northern high-latitudes and their relations to solar wind parameters, Philos. Trans. Royal Soc., A304, 253-301, 1982.

McComas, D. J., Bame, S. J., Barker, P., Feldman, W. C., Phillips, J. L., Riley, P., and Griffee, J. W.: Solar Wind Electron Proton Alpha Monitor (SWEPAM) for the Advanced Composition Explorer, Space Sci. Rev., 86, 563-612, 1998.

Newell, P. T., Meng, C.-I., Sibeck, D. G., and Lepping, R.: Some low-altitude cusp dependencies on the Interplanetary Magnetic Field, J. Geophys. Res., 94, 8921-8927, 1989.

Papitashvili, V. O. and Rich, F. J.: High-latitude ionospheric convection models derived from Defense Meteorological Satellite Program ion drift observations and parameterized by the interplanetary magnetic field strength and direction, J. Geophys. Res., 107, 1198, doi:10.1029/2001JA000264, 2002.

Papitashvili, V. O., Belov, B. A., Faermark, D. S., Feldstein, Y. I., Golyshev, S. A., Gromova, L. I., and Levitin, A. E.: Electric potential patterns in the northern and southern polar regions parameterized by the Interplanetary Magnetic Field, J. Geophys. Res., 99, 13251-13262, 1994.

Paschmann, G., Melzner, F., Frenzel, R., Vaith, H., Parigger, P., Pagel, U., Bauer, O. H., Haerendel, G., Baumjohann, W., Sckopke, N., Torbert, R. B., Briggs, B., Chan, J., Lynch, K., Morey, 
K., Quinn, J. M., Simpson, D., Young, C., McIlwain, C. E., Fillius, W., Kerr, S. S., Mahieu, R., and Whipple, E. C.: The Electron Drift Instrument for Cluster, Space Sci. Rev., 79, 233-269, 1997.

Paschmann, G., Quinn, J. M., Torbert, R. B., Vaith, H., McIlwain, C. E., Haerendel, G., Bauer, O. H., Bauer, T., Baumjohann, W., Fillius, W., Förster, M., Frey, S., Georgescu, E., Kerr, S. S., Kletzing, C. A., Matsui, H., Puhl-Quinn, P., and Whipple, E. C.: The Electron Drift Instrument on Cluster: overview of first results, Ann. Geophys., 19, 1273-1288, 2001, http://www.ann-geophys.net/19/1273/2001/.

Rich, F. J. and Hairston, M. R.: Large-scale convection patterns observed by DMSP, J. Geophys. Res., 99, 3827-3844, 1994.

Ruohoniemi, J. M. and Greenwald, R. A.: Dependencies of high-latitude plasma convection: Consideration of interplanetary magnetic field, seasonal, and universal time factors in statistical patterns, J. Geophys. Res., 110, A09204, doi:10.1029/ 2004JA010815, 2005.

Russell, C.: The configuration of the magnetosphere, in: Critical Problems of Magnetospheric Physics, edited by: Dyer, E., pp. 1-16, Nature Academy of Science, Washington, 1972.

Sandholt, P. E. and Farrugia, C. J.: Plasma flow channels at the dawn/dusk polar cap boundaries: momentum transfer on old open field lines and the roles of IMF $B_{y}$ and conductivity gradients, Ann. Geophys., 27, 1527-1554, 2009, http://www.ann-geophys.net/27/1527/2009/.

Shue, J.-H., Chao, J. K., Fu, H. C., Russell, C. T., Song, P., Khurana, K. K., and Singer, H. J.: A new functional form to study the solar wind control of the magnetopause size and shape, J. Geophys. Res., 102, 9497-9512, doi:10.1029/97JA00196, 1997.

Smith, C. W., L'Heureux, J., Ness, N. F., Acuña, M. H., Burlaga, L. F., and Scheifele, J.: The ACE magnetic fields experiment, Space Sci. Rev., 86, 613-632, 1998.

Sonnerup, B. U. Ö., Siebert, K. D., White, W. W., Weimer, D. R., Maynard, N. C., Schoendorf, J. A., Wilson, G. R., Siscoe, G. L., and Erickson, G. M.: Simulations of the magnetosphere for zero interplanetary magnetic field: The ground state, J. Geophys. Res., 106, 29419-29434, 2001.

Tanaka, T.: Configuration of the magnetosphere-ionosphere convection system under northward IMF conditions with nonzero IMF B ${ }_{y}$, J. Geophys. Res., 104, 14683-14690, 1999.
Tsyganenko, N. A.: A model of the near magnetosphere with a dawn-dusk asymmetry 1. Mathematical structure, J. Geophys. Res., 107, 1179, doi:10.1029/2001JA000219, 2002a.

Tsyganenko, N. A.: A model of the near magnetosphere with a dawn-dusk asymmetry 2. Parameterization and fitting to observations, J. Geophys. Res., 107, 1176, doi:10.1029/2001JA000220, 2002b.

Watanabe, M. and Sofko, G. J.: The interchange cycle: A fundamental mode of magnetic flux circulation for northward interplanetary magnetic field, Geophys. Res. Lett., 36, L03107, doi: 10.1029/2008GL036682, 2009a.

Watanabe, M. and Sofko, G. J.: Role of interchange reconnection in convection at small interplanetary magnetic field clock angles and in transpolar arc motion, J. Geophys. Res., 114, A01209, doi:10.1029/2008JA013426, 2009b.

Watanabe, M., Iijima, T., Nakagawa, M., Potemra, T. A., Zanetti, L. J., Ohtani, S., and Newell, P. T.: Field-aligned current systems in the magnetospheric ground state, J. Geophys. Res., 103, 68536870, 1998.

Watanabe, M., Kabin, K., Sofko, G. J., Rankin, R., Gombosi, T. I., Ridley, A. J., and Clauer, C. R.: Internal reconnection for northward interplanetary magnetic field, J. Geophys. Res., 110, A06210, doi:10.1029/2004JA010832, 2005.

Weimer, D. R.: Models of high latitude electric potentials derived with a least error fit of spherical harmonic coefficients, J. Geophys. Res., 100, 19595-19607, 1995.

Weimer, D. R.: Improved ionospheric electrodynamic models and application to calculating Joule heating rates, J. Geophys. Res., 110, A05306, doi:10.1029/2004JA010884, 2005.

Weimer, D. R., Ober, D. M., Maynard, N. C., Collier, M. R., McComas, D. J., Ness, N. F., Smith, C. W., and Watermann, J.: Predicting interplanetary magnetic field (IMF) propagation delay times using the minimum variance technique, J. Geophys. Res., 108, 1026, doi:10.1029/2002JA009405, 2003.

Woodfield, E. E., Dunlop, M. W., Holme, R., Davies, J. A., and Hapgood, M. A.: A comparison of Cluster magnetic data with the Tsyganenko 2001 model, J. Geophys. Res., 112, A06248, doi:10.1029/2006JA012217, 2007. 